\title{
Transmission line short circuit analysis by impedance matrix method
}

\author{
Boniface Onyemaechi Anyaka, Innocent Onyebuchi Ozioko \\ Department of Electrical Engineering, University of Nigeria, Nsukka, Enugu State, Nigeria
}

\begin{tabular}{l}
\hline \hline Article Info \\
\hline Article history: \\
Received Nov 30, 2018 \\
Revised Nov 1, 2019 \\
Accepted Nov 15, 2019 \\
\hline
\end{tabular}

\section{Keywords:}

Bus impedance matrix

Fault analysis

Power system

Symmetrical fault

Unsymmetrical fault

\begin{abstract}
Fault analysis is the process of determining the magnitude of fault voltage and current during the occurrence of different types of fault in electrical power system. Transmission line fault analysis is usually done for both symmetrical and unsymmetrical faults. Symmetrical faults are called three-phase balance fault while unsymmetrical faults include: single line-to-ground, line-to-line, and double line-to-ground faults. In this research, bus impedance matrix method for fault analysis is presented. Bus impedance matrix approach has several advantages over Thevenin's equivalent method and other conventional approaches. This is because the off-diagonal elements represent the transfer impedance of the power system network and helps in calculating the branch fault currents during a fault. Analytical and simulation approaches on a single line-to-ground fault on 3-bus power system network under bolted fault condition were used for the study. Both methods were compared and result showed negligible deviation of $0.02 \%$ on the average. The fault currents under bolted condition for the single line-to-ground fault were found to be $4.7244 \mathrm{p} . \mathrm{u}$ while the bus voltage is $0.4095 \mathrm{p}$.u for buses 1 and 2 respectively and $0.00 \mathrm{p} . \mathrm{u}$ for bus 3 since the fault occurred at this bus. Therefore, there is no need of burdensomely connecting the entire three sequence network during fault analysis in electrical power system.
\end{abstract}

Copyright $(2020$ Institute of Advanced Engineering and Science. All rights reserved.

\section{Corresponding Author:}

Boniface Onyemaechi Anyaka,

Department of Electrical Engineering,

University of Nigeria, Nsukka, Enugu State, Nigeria.

Email: boniface.anyaka@unn.edu.ng

\section{INTRODUCTION}

The main objective of a power system is to ensure a continual supply of electricity to users and to reduce the outage time whenever abnormality occurs. But due to its complexity, it is practically impossible to avoid natural events that usually affect the steady supply of electricity to the end users. These events comprise of lightning, equipment fatigue, accident, e. t. c which will definitely result in the loss of power on the system. When these events occur, fault is said to have occurred and there is need to analyze the system to clear the fault and restore the system to its normal working condition. It is easier to analyze fault in a power system by first knowing the type of fault that occurred. Faults on power systems can be divided into: (i) Three phase balanced faults or symmetrical faults which is a type of fault that affects all the three phases equally, (ii) Unbalanced faults or unsymmetrical faults which are faults that involve only one or two phases [1-5]. The occurrence of fault in power system is highly detrimental which usually cause loss of power. During this abnormal condition, high current flow is observed in the system which requires critical analysis of the system to obtain the voltage and current status of the system respectively. The analysis of the system helps to obtain the adequate safety and protection scheme to be applied for its optimal operation [6-8]. The magnitude of the fault voltage and current must be accurately calculated in order that mechanical and thermal stresses on equipment may be estimated for; choice of system layout, breaking capacities of switch and fuse gear, ratings of plant and types or choice of protective devices and their settings [7, 9-11]. 
There are various types of faults in electrical power systems. Some of them are classified as transient fault and persistent fault. Transient fault disappears once there is outage in the system. This kind of fault occurs majorly on overhead transmission lines. Power system protection are usually applied to safeguard the system. Persistent fault last for long in the power system and usually occurs in underground cable. Sometimes, fault in underground cable is transitory as a result of lightning. These types of faults can be classified as balance and unbalanced faults. A three-phase symmetrical fault, otherwise called three phase balanced fault, is the most severe of all the types of faults. It affects the three phases equally [12-13]. This is in contrast to an unsymmetrical fault, where the three phases are not affected equally. Unsymmetrical fault comprises of; single line-to-ground fault, line-to-line fault and double line-to-ground fault. The most frequently occurrence fault is the single line-to-ground fault, followed by line-to-line fault, double line-to-ground fault and lastly the three phase fault. This shows that unsymmetrical fault is the most frequently occurrence type of fault and the most complex. Forced outages can be associated with aging equipment/defects, lightning, and wind, birds/animals, vandalism, and accidents, e. t. c [12]. In real situation, majority of breakdowns in the network are caused by unbalanced faults. Therefore, symmetrical faults are seen as perceptions. The analysis of unsymmetrical fault is based on the understanding of symmetrical fault [14].

In other to analyze any unbalanced power system, one has to have the knowledge and use of symmetrical components to solve such system using a balanced representation [15]. This method is considered the base of all traditional fault analysis approaches of solving unbalanced power system [16-23]. The theory suggests that any unbalanced system can be represented by a number of balanced systems equal to the number of its phasors. The balanced system representations are called symmetrical components. In three-phase system, there are three sets of balanced symmetrical components that can be obtained; the positive, negative and zero sequence components. The positive sequence consists of set of phasors which has the same original system sequence. The second set of phasors has an opposite sequence which is called the negative sequence. The zero sequence has three components in phase with each other. The symmetrical components approach is a powerful tool that makes the analysis of unsymmetrical fault as simple as the analysis of a symmetrical fault.

Unsymmetrical fault can be analyzed first by developing the three sequences - (positive-, negative -, and zero-sequence) network of the power system case study. Also, Thevenin equivalent circuit as viewed from the faulty point has to be obtained in other to calculate the sequence fault currents of the system. Similarly, to calculate the branch currents and bus voltage at each bus of a three-phase system, you need to connect three sequence networks individually when analyzing each of the fault types. This may result to a tedious work in drawing the systems circuit. Secondly, the relevance of impedance bus matrix approach will not be valid if the sequence networks connections are used in the course of fault analysis.

However, these two setbacks on using sequence networks to analyze fault can be overcome using bus impedance matrix method [16]. This method analyzes the basic n-bus network to obtain the bus admittance matrix ( $\mathrm{Y}_{\text {bus }}$ ), from the line impedance. Bus impedance matrix method is used to analyze any kind of fault since the approach contains the transfer impedances between the buses. Thus, bus impedance matrix method consumes less time when compared with Thevenin's approach. This method has another advantage over traditional method because it is better to use matrix approach to analyze complex power system fault [24-26]. Figures 1-3 represents the different types of unbalanced faults in electrical power system network.

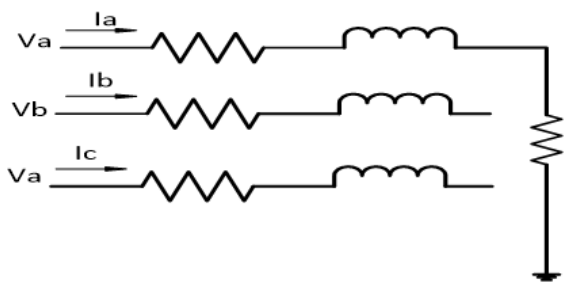

Figure 1. Single line-to-ground fault

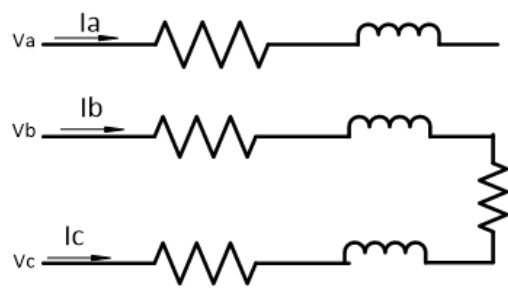

Figure 2. Line-to-line fault

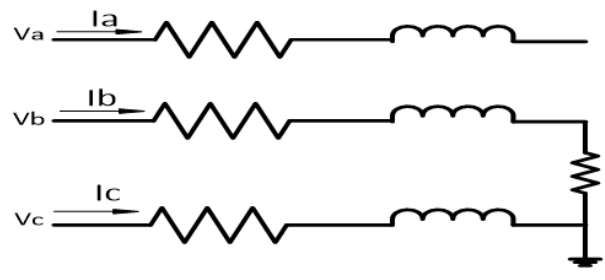

Figure 3. Double line-to-ground fault 


\section{RESEARCH METHOD}

The bus impedance matrix approach was used in carrying out the study. We can work out a universal representation of all the symmetrical and unsymmetrical faults in a three-phase system. This representation is valid with the imposition of different fault boundary conditions. Admittance and impedance matrix were developed from the system's network which helps in calculation of fault currents and fault voltages. The following steps were used in developing the bus admittance matrix or $Y_{b u s}$ for an n-bus system;

a. The bus admittance matrix is symmetric.

b. The diagonal of self-admittance $\left(Y_{i i}\right)$ is equal to the sum of the primitive admittances of all the components connected to the $i$-th node or bus.

c. The off-diagonal element $\left(Y_{i j}\right)$ or $i j$-th element is equal to the negative of the primitive admittance at all components connected between nodes $i$ and $j$.

d. Bus admittance matrix is inversely to the bus impedance matrix.

Therefore, following the above steps, the admittance matrix of $n$-bus system can be developed as shown in (1).

$$
Y_{b u s}^{s}=\left[\begin{array}{ccccc}
Y_{11}^{s} & Y_{12}^{s} & Y_{13}^{s} & \cdots & Y_{1 n}^{s} \\
Y_{21}^{s} & Y_{22}^{s} & Y_{23}^{s} & \cdots & Y_{1 n}^{s} \\
\vdots & \vdots & & \vdots & \\
Y_{n 1}^{s} & Y_{n 2}^{s} & Y_{n 3}^{s} & \cdots & Y_{n n}^{s}
\end{array}\right]
$$

Thus $\quad Z_{b u s}^{s}=\left[Y_{b u s}^{s}\right]^{-1}$

Where $Y_{\text {bus }}^{s}=$ the sequence admittance matrix of n-bus system, $\mathrm{S}=1,2$, and 0 which represent positive-, negative-, and zero-sequence respectively. We have to note that when a network is balanced, the symmetrical components impedances are diagonal. This helps to calculate $Z_{\text {bus }}$ separately for zero-, positive-, and negativesequence networks. These diagonal bus impedances are the Thevenin impedance to the point of fault. In other to obtain a solution for the various types of fault, the bus impedance matrix for each sequence network is obtained separately. Therefore, for fault occurring at bus $i$ of an n-bus system, the fault formula for the various types of faults like three phase balance fault, single line-to-ground fault, line-to-line fault, and double line-toground fault are summarized:

- Three-phase balanced fault

Since the zero and negative sequence network model does not have any source voltage

$V^{0}=V^{2}=0 ; I^{0}=I^{2}=0$.

However, the positive sequence model does have a source voltage $V_{(0)}$ and hence

$$
V_{i}^{1}=\mathrm{V}_{(0)}-\left[Z_{i 1}^{1} I_{1}^{1}+\ldots . .+Z_{i i}^{1} I_{i}^{1}+\ldots .+Z_{i n}^{1} I_{n}^{1}\right]
$$

Since currents in all the buses except the ith bus are zero

$$
I_{i}^{1}=\frac{V_{(0)}}{Z_{i i}^{1}}
$$

Assuming fault impedance to be $=Z_{f}$,

$$
I_{i}^{1}=\frac{V_{(0)}}{Z_{f+} Z_{i i}}
$$

To obtain the k-th bus voltage for other buses, we proceed as follows:

$$
V_{k}^{1}=V_{(0)}-Z_{i k}^{1} I_{i}^{1}
$$

- Single line to ground fault

For fault occurring at ith bus, $I_{i}^{1}=I_{i}^{2}=I_{i}^{0}$. Thus

$$
I_{i}^{1}=\frac{V_{(0)}}{Z_{i i}^{0}+Z_{i i}^{1}+Z_{i i}^{2}+3 Z_{f}}
$$

The phase current is thus

$$
I_{i}^{a}=3 I_{i}^{1}
$$


The k-th sequence bus voltages are obtained as follow:

$$
\begin{aligned}
V_{k}^{0} & =\frac{-Z_{i k}^{0} V_{(0)}}{Z_{i i}^{0}+Z_{i i}^{1}+Z_{i i}^{2}+3 Z_{f}} \\
V_{k}^{1} & =V_{(0)}-\frac{Z_{i k}^{1} V_{(0)}}{Z_{i i}^{0}+Z_{i i}^{1}+Z_{i i}^{2}+3 Z_{f}} \\
V_{k}^{2} & =\frac{-Z_{i k}^{2} V_{(0)}}{Z_{i i}^{0}+Z_{i i}^{1}+Z_{i i}^{2}+3 Z_{f}}
\end{aligned}
$$

- Line to line fault

For fault occurring at i-th bus, $V_{i}^{0}=I_{i}^{0}=0$ and $I_{i}^{1}=-I_{i}^{2}$. The positive sequence current is thus:

$$
I_{i}^{1}=\frac{V_{(0)}}{Z_{i i}^{1}+Z_{i i}^{2}+Z_{f}}-I_{i}^{2}
$$

Therefore, the k-th voltages are:

$$
\begin{aligned}
V_{k}^{1} & =V_{(0)}-\frac{Z_{i k}^{1} V_{(0)}}{Z_{i i}^{1}+Z_{i i}^{2}+Z_{f}} \\
V_{k}^{2} & =\frac{Z_{i k}^{2} V_{(0)}}{Z_{i i}^{1}+Z_{i i}^{2}+Z_{f}}
\end{aligned}
$$

- Double line to ground fault

In this type of fault, if fault occurs at i-th bus, the summation of the sequence currents is equal to zero. Thus,

$$
I_{i}^{0}+I_{i}^{1}+I_{i}^{2}=0
$$

Also, $V_{i}^{1}=V_{i}^{2}$

Applying these concepts in a multi-bus system, we have:

$$
\begin{aligned}
& I_{i}^{1}=\frac{V_{(0)}}{Z_{i i}^{1}+\frac{Z_{i i\left(Z_{i i}^{0}+3 Z_{f}\right)}^{2}}{Z_{i i}^{2}+Z_{i i}^{0}+3 Z_{f}}}=\frac{V_{(0)}\left(Z_{i i}^{2}+Z_{i i}^{0}+3 Z_{f}\right)}{\Delta Z} \\
& I_{i}^{2}=-\frac{V_{i(0)}-Z_{i i}^{1} I_{i}^{1}}{Z_{i i}^{2}}=-\frac{V_{(0)}\left(Z_{i i}^{0}+3 Z_{f}\right)}{\Delta Z} \\
& I_{i}^{0}=-\frac{V_{i(0)-Z_{i i}^{1} I_{i}^{1}}}{Z_{i i}^{0}+3 Z_{f}}=\frac{-Z_{i i}^{2} V_{(0)}}{\Delta Z}
\end{aligned}
$$

Where $\Delta Z=Z_{i i}^{1} Z_{i i}^{2}+Z_{i i}^{1}\left(3 Z_{f}+Z_{i i}^{0}\right)+Z_{i i}^{2}\left(3 Z_{f}+Z_{i i}^{0}\right)$

The sequence voltage at $\mathrm{k}$-th bus are given by

$$
\begin{aligned}
& V_{k}^{0}=-Z_{i k}^{0} I_{i}^{0} \\
& V_{k}^{1}=V_{(0)}-Z_{i k}^{1} I_{i}^{1} \\
& V_{k}^{2}=-Z_{i k}^{2} I_{i}^{2}
\end{aligned}
$$

The symmetrical components of fault current in line $\mathrm{i}$ to $\mathrm{j}$ is given by

$$
I_{i j}^{S}=\frac{V_{i}^{S}-V_{j}^{S}}{Z_{i j}^{S}}
$$

Where $\mathrm{i}=\mathrm{i}$-th faulted bus, $\mathrm{k}=\mathrm{n}$-th bus, $V_{(0)}=$ pre-fault voltage, and $\mathrm{S}=$ Sequence. 
- Mathematical Formulations

The mathematical calculation for the fault occurring at bus 3 of the power system network shown in Figure 4 is done firstly by obtaining the branch admittance of the system since it is before the fault. Therefore, the reactance from Table 1 is used to obtain the admittance of the network for positive-, negative- and zerosequence of the circuit. Thus, from Table 1, the admittance of the zero-sequence power system is as follows;

Table 1. Power system network data [12]

\begin{tabular}{cclll}
\hline LINE NO. & BUS CODE & \multicolumn{3}{c}{ LINE IMPEDANCE } \\
\hline & & $\mathrm{X}^{0}$ & $\mathrm{X}^{1}$ & $\mathrm{X}^{2}$ \\
1 & $1-2$ & $\mathrm{j} 0.12$ & $\mathrm{j} 0.2$ & $\mathrm{j} 0.2$ \\
2 & $2-3$ & $\mathrm{j} 0.12$ & $\mathrm{j} 0.2$ & $\mathrm{j} 0.2$ \\
3 & $1-3$ & $\mathrm{j} 0.12$ & $\mathrm{j} 0.2$ & $\mathrm{j} 0.2$ \\
4 & $1-0$ & $\mathrm{j} 0.12$ & $\mathrm{j} 0.2$ & $\mathrm{j} 0.3$ \\
5 & $2-0$ & $\mathrm{j} 0.12$ & $\mathrm{j} 0.2$ & $\mathrm{j} 0.3$ \\
\hline
\end{tabular}

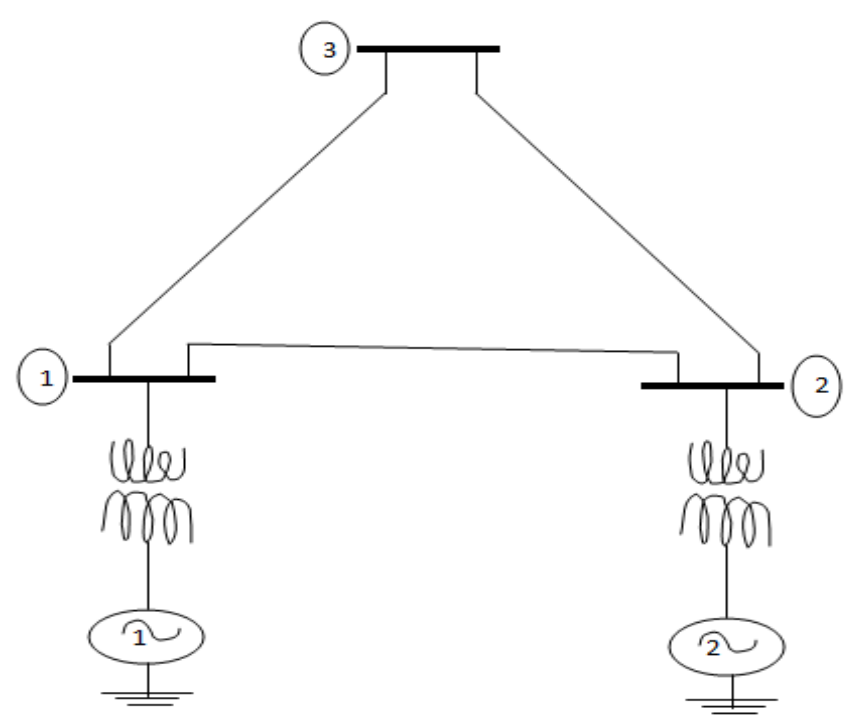

Figure 4. One-line diagram of a three-bus system [12]

$Y_{12}=Y_{21}=\frac{1}{Z_{12}}=\frac{1}{j 0.12}=-\mathrm{j} 8.3333$

$Y_{13}=Y_{31}=\frac{1}{Z_{13}}=\frac{1}{j 0.12}=-\mathrm{j} 8.3333 Y_{23}=\frac{1}{Z_{23}}$

$Y_{10}=\frac{1}{Z_{10}}=\frac{1}{j 0.15}=-\mathrm{j} 6.6667$

$Y_{20}=\frac{1}{Z_{20}}=\frac{1}{j 0.15}=-\mathrm{j} 6.6667 \quad Y_{23}=Y_{32}$

$Y_{11}=-\mathrm{j} 23.3333^{\prime}$

$Y_{22}=-\mathrm{j} 23.3333$

$Y_{33}=-\mathrm{j} 16.6667$

The bus admittance matrix is;

$$
Y_{\text {bus }}=\left[\begin{array}{lll}
Y_{11} & Y_{12} & Y_{13} \\
Y_{21} & Y_{22} & Y_{23} \\
Y_{31} & Y_{32} & Y_{33}
\end{array}\right]
$$


Therefore; the zero-sequence impedance matrix is thus:

$$
Y_{\text {bus }}^{0}=\left[\begin{array}{ccc}
-j 23.333 & j 8.3333 & j 8.3333 \\
j 8.3333 & -j 23.3333 & j 8.3333 \\
j 8.3333 & j 8.3333 & -j 16.6667
\end{array}\right]
$$

Thus: $\quad Z_{\text {bus }}^{0}=\operatorname{inv}\left[Y_{\text {bus }}^{0}\right]$

$$
\text { Therefore, } Z_{\text {bus }}^{0}=\left[\begin{array}{lll}
j 0.0089 & j 0.0592 & j 0.0750 \\
j 0.0592 & j 0.0908 & j 0.0750 \\
j 0.0750 & j 0.0750 & j 0.1350
\end{array}\right]
$$

Also, for positive- and negative-sequence, the admittance and impedance are as follows:

$$
\begin{array}{ll}
Y_{12}=Y_{21}=-\mathrm{j} 5 & Y_{23}=Y_{32}=\frac{1}{j 0.2}=-\mathrm{j} 5 \\
Y_{13}=Y_{31}=\frac{1}{j 0.2}=-\mathrm{j} 5 & Y_{10}=\frac{1}{J 0.3}=-\mathrm{j} 3.3333 \\
Y_{20}=\frac{1}{J 0.3}=-\mathrm{j} 3.3333 & Y_{11}=-\mathrm{j} 13.3333 \\
Y_{22}=-\mathrm{j} 13.3333 & Y_{33}=-\mathrm{j} 10 \\
Z_{\text {bus }}^{1}=Z_{\text {bus }}^{2}=\mathrm{inv}\left[Y_{\text {bus }}^{1}\right]=\mathrm{inv}\left[\begin{array}{ccc}
-j 13.3333 & j 5 & j 5 \\
j 5 & -j 13.3333 & j 5 \\
j 5 & j 5 & -j 10
\end{array}\right] \\
Z_{\text {bus }}^{1}=Z_{\text {bus }}^{2}=\left[\begin{array}{lll}
j 0.1773 & j 0.1227 & j 0.1500 \\
j 0.1227 & j 0.1773 & j 0.1500 \\
j 0.1500 & j 0.1500 & j 0.2500
\end{array}\right]
\end{array}
$$

(i) Symmetrical components of the currents with a pre-fault voltage $V_{(0)}=1.0 \mathrm{p}$.u is given by

$$
I_{3}^{0}=I_{3}^{1}=I_{3}^{2}=\frac{1}{Z_{33}^{1}+Z_{33}^{2}+Z_{33}^{0}}=-\mathrm{j} 1.5748
$$

(ii) Phase current is

$$
\left[\begin{array}{l}
I_{3}^{a} \\
I_{3}^{b} \\
I_{3}^{c}
\end{array}\right]=\left[\begin{array}{ccc}
1 & 1 & 1 \\
1 & \beta^{2} & \beta \\
1 & \beta & \beta^{2}
\end{array}\right]\left[\begin{array}{l}
-\mathrm{j} 1.5748 \\
-\mathrm{j} 1.5748 \\
-\mathrm{j} 1.5748
\end{array}\right]=\left[\begin{array}{c}
4.7244 \\
0 \\
0
\end{array}\right] \mathrm{p} . \mathrm{u}
$$

(iii) The symmetrical components voltage for all the buses is

Bus-1

$$
\left[\begin{array}{c}
V_{1}^{0} \\
V_{1}^{1} \\
V_{1}^{2}
\end{array}\right]=\left[\begin{array}{c}
-Z_{13}^{0} I_{3}^{0} \\
V_{(0)}-Z_{13}^{1} I_{3}^{1} \\
-Z_{13}^{2} I_{3}^{2}
\end{array}\right]=\left[\begin{array}{c}
-0.1181 \\
0.7638 \\
-0.2362
\end{array}\right] \mathrm{p} . \mathrm{u}
$$

Bus-2

$$
\left[\begin{array}{c}
V_{2}^{0} \\
V_{2}^{1} \\
V_{2}^{2}
\end{array}\right]=\left[\begin{array}{c}
-Z_{23}^{0} I_{3}^{0} \\
V_{(0)}-Z_{23}^{1} I_{4}^{1} \\
-Z_{23}^{2} I_{3}^{2}
\end{array}\right]=\left[\begin{array}{c}
-0.1181 \\
0.7638 \\
-0.2362
\end{array}\right] \text { p.u }
$$

Bus-3

$$
\left[\begin{array}{l}
V_{3}^{0} \\
V_{3}^{1} \\
V_{3}^{2}
\end{array}\right]=\left[\begin{array}{c}
-Z_{33}^{0} I_{3}^{0} \\
V_{(0)}-Z_{33}^{1} I_{3}^{1} \\
-Z_{33}^{2} I_{3}^{2}
\end{array}\right]=\left[\begin{array}{c}
-0.2126 \\
0.6063 \\
-0.3937
\end{array}\right] \mathrm{p} . \mathrm{u}
$$


(iv) Bus voltages during the fault are

Bus-1

$$
\left[\begin{array}{l}
V_{1}^{a} \\
V_{1}^{b} \\
V_{1}^{c}
\end{array}\right]=\left|\left[\begin{array}{ccc}
1 & 1 & 1 \\
1 & \beta^{2} & \beta \\
1 & \beta & \beta^{2}
\end{array}\right]\left[\begin{array}{c}
-0.1181 \\
0.7638 \\
-0.2362
\end{array}\right]\right|=\left[\begin{array}{l}
0.4095 \\
0.9466 \\
0.9466
\end{array}\right] \mathrm{p} . \mathrm{u}
$$

Bus-2

$$
\left[\begin{array}{l}
V_{2}^{a} \\
V_{2}^{b} \\
V_{2}^{c}
\end{array}\right]=\left|\left[\begin{array}{ccc}
1 & 1 & 1 \\
1 & \beta^{2} & \beta \\
1 & \beta & \beta^{2}
\end{array}\right]\left[\begin{array}{c}
-0.1181 \\
0.7638 \\
-0.2362
\end{array}\right]\right|=\left[\begin{array}{l}
0.4095 \\
0.9466 \\
0.9466
\end{array}\right] \mathrm{p} . \mathrm{u}
$$

Bus-3

$$
\left[\begin{array}{l}
V_{3}^{a} \\
V_{3}^{b} \\
V_{3}^{c}
\end{array}\right]=\left[\begin{array}{ccc}
1 & 1 & 1 \\
1 & \beta^{2} & \beta \\
1 & \beta & \beta^{2}
\end{array}\right]\left[\begin{array}{c}
-0.2126 \\
0.6063 \\
-0.3937
\end{array}\right]=\left[\begin{array}{c}
0 \\
0.9229 \\
0.9229
\end{array}\right] \text { p.u }
$$

(v) The symmetrical components of fault currents in lines for phase "a" are: For Line 2 to 1

$$
\left[\begin{array}{l}
I_{21}^{0} \\
I_{21}^{1} \\
I_{21}^{2}
\end{array}\right]=\left[\begin{array}{c}
\frac{\left(V_{2}^{0}-V_{1}^{0}\right)}{Z_{21}^{0}} \\
\frac{\left(V_{2}^{1}-V_{1}^{1}\right)}{Z_{21}^{1}} \\
\frac{\left(V_{2}^{2}-V_{1}^{2}\right)}{Z_{21}^{2}}
\end{array}\right]=\left[\begin{array}{c}
\frac{(-0.1181-(-0.1181))}{j 0.12} \\
\frac{(0.7638-0.7638)}{j 0.2} \\
\frac{-0.2322-(-0.2322)}{j 0.2}
\end{array}\right]=\left[\begin{array}{l}
0 \\
0 \\
0
\end{array}\right]
$$

For line 3 to 1

$$
\left[\begin{array}{l}
I_{31}^{0} \\
I_{31}^{1} \\
I_{31}^{2}
\end{array}\right]=\left[\begin{array}{l}
\frac{\left(V_{3}^{0}-V_{1}^{0}\right)}{Z_{31}^{0}} \\
\frac{\left(V_{3}^{1}-V_{1}^{1}\right)}{Z_{31}^{1}} \\
\frac{\left(V_{3}^{2}-V_{1}^{2}\right)}{Z_{31}^{2}}
\end{array}\right]=\left[\begin{array}{c}
\frac{(-0.2126-(-0.1181))}{j 0.12} \\
\frac{(0.6063-0.7638)}{j 0.2} \\
\frac{(-0.3937-(-0.2362))}{j 0.2}
\end{array}\right]=\left[\begin{array}{l}
j 0.7875 \\
j 0.7875 \\
j 0.7875
\end{array}\right]
$$

For line 2 to 3

$$
\left[\begin{array}{l}
I_{23}^{0} \\
I_{23}^{1} \\
I_{23}^{2}
\end{array}\right]=\left[\begin{array}{l}
\frac{\left(V_{2}^{0}-V_{3}^{0}\right)}{Z_{23}^{0}} \\
\frac{\left(V_{2}^{1}-V_{3}^{1}\right)}{Z_{23}^{1}} \\
\frac{\left(V_{2}^{2}-V_{3}^{2}\right)}{Z_{23}^{2}}
\end{array}\right]=\left[\begin{array}{c}
\frac{(-0.1181-(-0.2126))}{j 0.12} \\
\frac{(0.7638-0.6063)}{j 0.2} \\
\frac{(-0.2362-(-0.3937))}{j 0.2}
\end{array}\right]=\left[\begin{array}{l}
-j 0.7875 \\
-j 0.7875 \\
-j 0.7875
\end{array}\right]
$$

(vi) The line currents are:

For Line 2 to 1

$$
\left[\begin{array}{l}
I_{21}^{a} \\
I_{21}^{b} \\
I_{21}^{c}
\end{array}\right]=\left[\begin{array}{ccc}
1 & 1 & 1 \\
1 & \beta^{2} & \beta \\
1 & \beta & \beta^{2}
\end{array}\right]\left[\begin{array}{l}
0 \\
0 \\
0
\end{array}\right]=\left[\begin{array}{l}
0 \\
0 \\
0
\end{array}\right]
$$

For line 3 to 1

$$
\left[\begin{array}{l}
I_{31}^{a} \\
I_{31}^{b} \\
I_{31}^{c}
\end{array}\right]=\left[\begin{array}{ccc}
1 & 1 & 1 \\
1 & \beta^{2} & \beta \\
1 & \beta & \beta^{2}
\end{array}\right]\left[\begin{array}{l}
j 0.7875 \\
j 0.7875 \\
j 0.7875
\end{array}\right]=\left[\begin{array}{c}
2.3625 \\
0 \\
0
\end{array}\right] \text { p. u }
$$

For line 2 to 3

$$
\left[\begin{array}{l}
I_{23}^{a} \\
I_{23}^{b} \\
I_{23}^{c}
\end{array}\right]=\left[\begin{array}{ccc}
1 & 1 & 1 \\
1 & \beta^{2} & \beta \\
1 & \beta & \beta^{2}
\end{array}\right]\left[\begin{array}{l}
-j 0.7875 \\
-j 0.7875 \\
-j 0.7875
\end{array}\right]=\left[\begin{array}{c}
2.3625 \\
0 \\
0
\end{array}\right] \mathrm{p} . \mathrm{u}
$$




\section{RESULTS AND ANALYSIS}

The results of the analysis are in Figures 5 and 6. Figure 5 represents bus voltage against phase and Figure 6 represents the branch current against line of the system respectively. Figure 5(a) represents the phase voltages of buses 1-3 for analytical approach while Figure 5(b) is the results for the simulation method. Figure 6(a) represents the branch current for analytical method while Figure 6(b) shows the branch current for simulation approach.

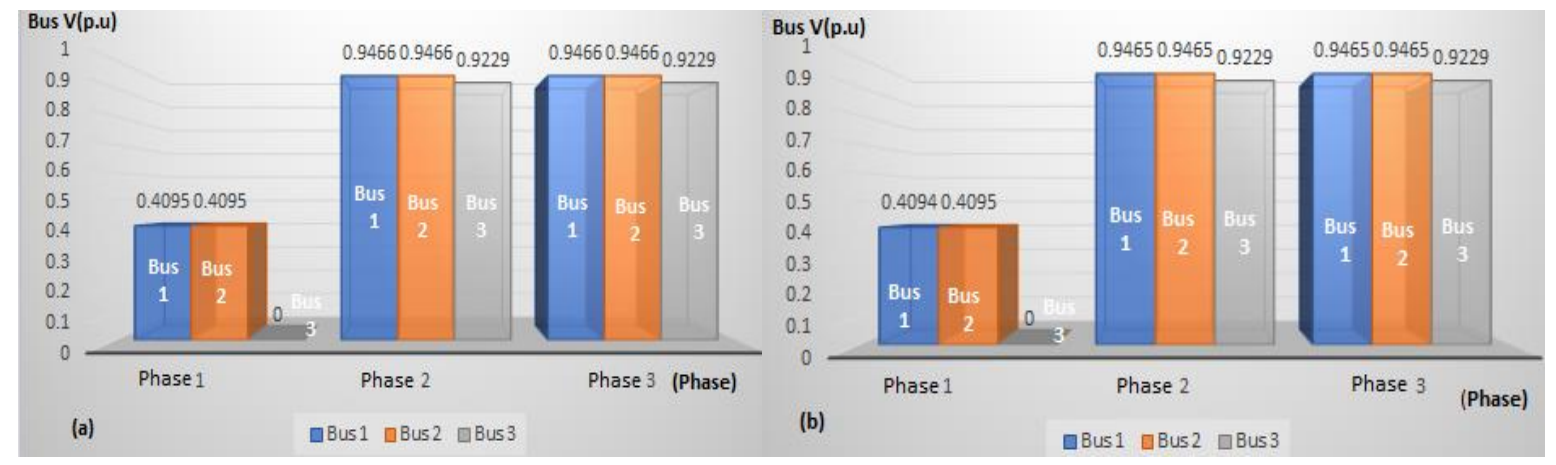

(a) (b)

Figure 5. Plots of bus voltage against phase; (a) analytical method, (b) simulation method

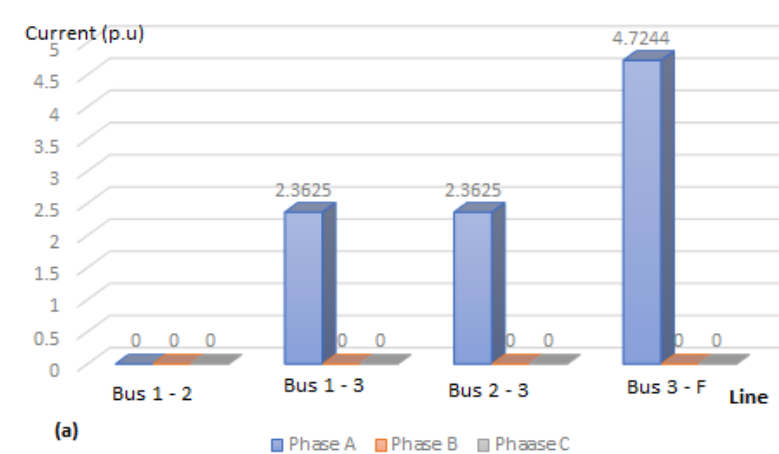

(a)

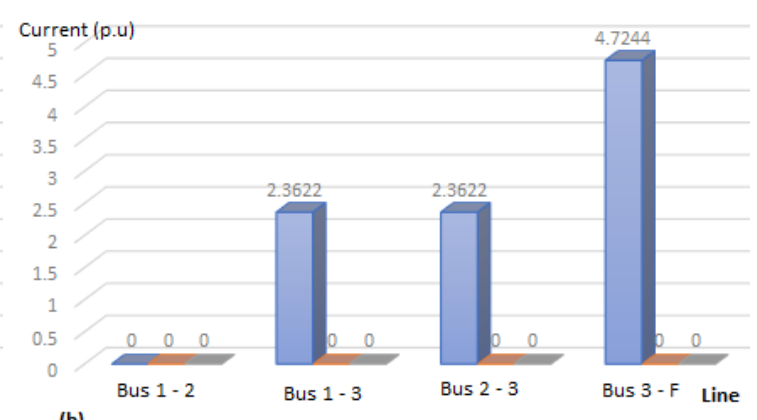

(b)

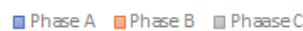

(b)

Figure 6. Plots of branch current against line; (a) analytical method, (b) simulation method

From the results presented in Figure 5, it can be seen that both approaches showed a negligible deviation in the range of $0.02 \%$ on the average. The simulation results showed a high speed of about 1 second and accuracy of $99.98 \%$. Phase 1 showed a zero (0p. u) voltage magnitude at bus 3 because (Single - line to - ground) fault occurred at bus 3 and that affected mostly the magnitude voltage level of other buses of the same phase and less on those phases that fault did not occur. It can also be seen that the fault voltages of the various buses are less than the pre-fault voltage which could be as a result of change in line flow due to fault in the system. Figure 6 represents the branch fault currents of the system. It is observed that the line current between the buses not connected to bus 3 gave a zero-magnitude fault current for all the phases while line 1-3 and line 2-3 show an equal current at phase a of the system. The total fault current at bus 3 is represented as 3 to point $F$ where $F$ represents the fault point and is the summation of all the line currents connected at bus 3 .

\section{CONCLUSION}

Fault in electrical power system is inevitable. Therefore, the rating and setting of all the protective devices requires appropriate analysis of fault voltage and current during the occurrence of fault on electrical power system. This will enhance the safety of equipment/persons and hence increase the reliability of the system. In this work, unbalance fault on a 3-bus power network was analyzed to obtain the fault voltage, branch current at the respective buses during the occurrence of fault and the total current at bus 3 . The analysis

Transmission line short circuit analysis by impedance matrix method (Boniface Onyemaechi Anyaka) 
was done based on bolted fault. From the results, it was found that when a fault occurs at a particular bus, its bus voltage becomes zero for a three-phase fault. This is shown at bus 3 of Figure 5. It is also observed that during fault, voltage at the respective buses reduced below the pre-fault voltage which shows the abnormality in the system. Also, high magnitude of fault current was observed during bolted fault which is as a result of low fault impedance of the system. Therefore, any protective device for this power system must not be rated below 4.7244A to enhance reliable system reliability. With the accuracy and speed of the simulation approach, power system performance must be improved if applied.

\section{REFERENCES}

[1] H. Saadat "Power System Analysis," McGraw-Hill Companies, inc. USA, 1999.

[2] A. O. Ekwue "Worked examples in Power System Engineering", University of Nigeria Press Ltd, 2015.

[3] J. B. Gupta, "Power System", Ram Nagar New Daily India. Sajeev Kumar Katar and Sons. p.480, 2010.

[4] S. E. G. Mohamed, A.Y Mohamed, and Y.H Abdelrahim, "Power System Contingency Analysis to Detect Network Weakness", Zaytoonah University International Engineering Conference on Design and innovation in Infrastructure, Ammam, Jordan, pp. 13-24, June, 2012.

[5] J. D. Glover, M. S. Sarma, T. J. Overby, "Power System Analysis and Design" $5^{\text {th }}$ ed. Stamford Cengage Learning, 2012.

[6] S. Mahapatra and M. Singh "Symmetrical Fault Analysis", International Journal of Future Generation Communication and Networking, Vol. 9, No. 4, pp 51-62, 2016.

[7] G. A. Adepoju, O. A. Komolafe, M. A Tijani and A. O. Bisiriyu, "Fault Analysis for Circuit Breakers Ratings Determination on Nigerian 330kV Transmission Grid," the International Journal of Engineering and Science (IJES), Vol. 2, No. 3, pp 116-123, 2013.

[8] G. Andersson "power system analysis," Swiss Federal Institute of Technology, Zuric, Eidgenossische Technische Hochschule Zuric, Sept. 2012.

[9] D. Tziouvaras "Analysis of Complex Power System Faults and Operating Conditions," Schweitzer Engineering Laboratories, Inc. 2008/2009.

[10] C. Li-am, "Prediction of Magnitude of Short Circuit Current in Power Distribution System" IEEE International Symposium on Computer Science and Society, Xiaman, 2011.

[11] A. kalyuzhny, "Analysis of Temporary Over Voltages during Open-Phase Fault in Distribution Networks with Resonant Grounding, IEEE Trans. Power Del., Vol.30, NO. 1 pp. 420-427, Feb. 2015.

[12] S. Srivastava, Km. Reshu, and S. Singh "Mathematical Calculation and MATLAB Programming of Symmetrical and Asymmetrical Faults in Power System," International Journal of Engineering Management Research, Vol. 4, No. 2, pp 184-187, April 2014.

[13] G. A. Ajenikoko and S. O. Sangotola, "Power System Fault: A Hindrance to Sustainability and Reliability", International Journal of Engineering Research, Vol. 3, No. 11, pp 700-703, 01 Nov. 2014.

[14] O. S. Onohaebi, "Power Outages in Nigeria Transmission Grid," Journal of Applied Science, Vol. 4, No. 1, pp 1-9, 2009.

[15] D. C. Yu, D. Chen, S. Ramasany and D. G. Flin "A Windows Based Graphical Package for Symmetrical Component Analysis," IEEE Trans. on Power System. Vol. 10, No. 4, PP 1742-1749.

[16] P. V. Dhole and F.S. Khan "Transmission Line Fault Analysis Using Bus Impedance Matrix Method," International Journal of Engineering Research and Technology (IJERT), Vol. 4, No. 3, pp 948-954, March 2015.

[17] A. Chakrabarti and S. Halder "Power System Analysis Operation and Control," PHI Learning Private Limited, Third Edition, New Delhi, 2011.

[18] J.B. Gupta. "Electrical Technology: Basic Electrical Engineering," S.K Kataria \& Son Publishing Company, Daryaganj, Delhi, 2010

[19] B.R. Gupta. "Power System Analysis and Design," S Chand \& Company Ltd, Ram Najar New Delhi, 2006.

[20] D.P. Kothari \& I.J Nagrath. "Modern Power System Analysis," Tata McGraw Hill Publishing Company Ltd, Third Edition, New Delhi. 2003.

[21] B.M. Weedy, B.J Cory, N. Jerkins, J.B Ekanayake, G Stubac. "Electric Power Systems, Fifth Edition. John Willy \& Sons Ltd Publication

[22] A.J wood, B. F. Wallenberg, "Power Generation, Operation and Control" $2^{\text {nd }}$ ed. New Yok/USA: John Wiley \& Sons, pp. 410-432, 1996.

[23] J. D. Glover, T. J. Overby, M. S. Sarma, "System Protection in Power System and Design”, Stamford, Global Engineering and Cengage Learning, pp. 516, 2012.

[24] V. K Meha, R. Meha, "Principles of Power System", New Daily, India. S. Chaid and Company Limited. pp.587-590, 2010.

[25] F. B. Costa, B. A. Souza, N. S. D. Brito, J. A. C. B. Silva, W. C. Santos, "Real-Time Detection of Transients Induced by High-Impedance Fault Based on Boundary Wave length Transform" IEEE Transactions on Industrial Application, Vol. 51, NO. 6, pp 5312-5323, May, 2015.

[26] K. Nara, K. Tanaka, H. Kodama, R. Shoults, M.S Chen, P.V Olimda and D. Bertagnolli, "On-Line Contingency Selection for Voltage security Analysis”, Ibid, Vol. PAS-104, pp.847-856, April 1985. 


\section{BIOGRAPHIES OF AUTHORS}

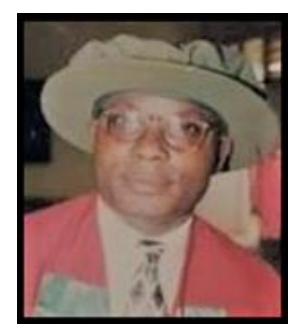

Boniface O. Anyaka is currently a Senior Lecturer in the Department of Electrical Engineering, Faculty of Engineering, University of Nigeria, Nsukka, Nigeria. He had his M.Eng in Electric Power System/Applied Automatics from the University of Technology, Wroclaw, Poland in 1988 and his Ph.D. from the Department of Electrical Engineering. University of Nigeria, Nsukka in 2011. He has held a number of positions in the university system. He was the director, student's industrial work experience scheme (SIWES), University of Nigeria Nsukka and Enugu campuses between 2006 and 2007. He was the acting Head, Department of Electrical Engineering, University of Nigeria, Nsukka (2011-2013) and the immediate past Associate Dean, Faculty of Engineering, University of Nigeria, Nsukka (2016-2018). Engr. Dr. Anyaka is a registered member of the Council for the Regulation of Engineering in Nigeria (COREN), corporate member, Nigeria Society of Engineers (NSE), member, Solar Energy Society of Nigeria (SESN), and Member Nigeria Institution of Electrical and Electronic Engineers (NIEEE). His major field of research interest is in the area of power system modelling and renewable energy (Photovoltaic). He has to his credit, over 50 publications in both local and international journals.

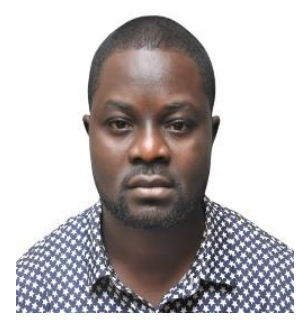

Innocent O. Onyebuchi had his M.Eng degree in Electrical Power Systems and High Voltage Engineering from the Department of Electrical Engineering, University of Nigeria, Nsukka in 2017. He is currently a Ph.D student in the same department. 